\title{
Present Day Problems of Plant Geography-II*
}

\author{
As Related to the Necessity for Intensified Production
}

By Jean Dufrenoy, Assistant at the Arachon Biological Laboratories

[Concluded from Scientific American Suppiement No. 2207, April 20, 1918]

II. GENETIC AND MORPHOGENY

1.-Ficctuating variations and profound variations

ALL living creatures vary under the influence of ecologic factors. "A new creature is not merely one more proof from a plate stereotyped once for all" (Baudement). Variations always affect not only the different plants of the same group, but the different parts of the same individual. ${ }^{41}$

Most of ten these variations are of slight amplitude all the intermediates $\mathrm{s}^{42}$ are found between their extremes; the name of fluctuations, or oscillating varia tions, given to them, therefore, shows that it is necessary to regard them as oscillations of morphologic or physiologic equilibrium around a middle position.

The profound variations which cause an individual very different from its near relations to appear in a species are distinguished by their greater amplitude and by certain features lacking in the intermediates.

§ 2.-The cause of variations

To what modifying agents can variations be attributed? In the first place to crossing.s between different types (vicinism), and some biologists consider this to be the sole possidele rause of the so-called abrupt variations or mutations. In the next place to living and non-lining factors of the environment. A given environment, a given flora.

For a similar area the more varied the physiugraphy of the region the more varied the flora. ${ }^{4}$

In any flora the proportion of the genera to the species (Jaccard's generic coefficient) is inversely pro portional to the diversity of the ecologic conditions, in uniform country (the dunes of Morocco) there is only one species to each genus; in very broken country (Switzerland) each genus contains three or four, or a large number of species, according to the habitat.

The diversity of organisms is simply the result of the modeling by ecologic conditions of a small number of fundamental forms.

The fact is that "there is no more sensitive reagent than living matter; it is flexible enough to adapt it self to all the variations of the exterior and the interior milieu." A given milieu, a given plant.

The facts of adaptation to soils and to parasite are well known: it was in America, the land of the phylloxera, that there were found the vine-stocks resistant to the insect; it is in the Roman campagna, a humid country, that we find the wheats resistant a humid country, that we find
to cryptograms (Rieti wheats).

Superalimentation exaggerates the development of the vegetative organs, enabling the horticulturist to obtain double flowers by the sterilization of the stamens. It provokes tuberization and transforms the wild car rot into the cultivated carrot, the wild beet (Beta maritima) into the sugar beet, ${ }^{40}$ the night shade (So maritima) into the sugar beet, ${ }^{45}$ the night shade (So-
lanum Commersonii and $S$. Maglia) into the edible potato of heavy yield. ${ }^{\text {so }}$

Lack of food, on the other hand, hunger, prevents the tuberization of radishes." Thirst diminishes the production of vegetative organs and makes the flowers appear prematurely on soils which are sloping, sandy or dried by the wind. This is shown by observation of the cycle of evolution of the Cakile maritima, at different points of the Arcachon Basin.48

In the inflorescena of the maritime pine of the littoral the action of the maritime wind causes the staminal leaves of the periphery of the male flowers to develop into sterile parts, into a protective perianth. Between these sterilized scales the floral branch elon gates its internodes, assuming the aspect of a growing branch, or rather, suddenly arrested in its development,

*Translated for the Scientific American Supplemen from Revue generale des Sciences.

"Schribaux: General Agriculture.
42Mallère: Zootechnology (course offered at Agronomic In stitute). 43.J. W. Harshberger: The Diversity of Ecologic Condi-
tions and its Influence on the Richness of Floras. Proceed, Acad Not. Sc. Phila., p. 419-425, A ug. 1915 .

"JJ. R. Carracido: The Foundations of Biochemistry, Scientia, I-II, p. 137,1917

"Helot, Proskowetz, Schindler, J. Dufrenoy.

${ }^{4}$ Labergerie, Heckel.

${ }^{47}$ Mile. Trouard-Riolle : Experimental Researches on Radishe * * * Ann. Sc. Agronom. Fr. et étrang., 1914 "8 These seeds germinate in the spring; $25 \%$ of the embryos
are monocotyledons. it remains rudimentary, and takes the characters of the female flower. ${ }^{40}$ Inversely the cone bearing branches cease to produce anything but male flowers when they are shaded by the new branches or enfeebled by any other external cause. ${ }^{\text {s0 }}$

A change in the milieu often affects the sexuality :5 of the 200 species of plants which MacDougal ${ }^{52}$ had transported to the tops of mountains, the seashore, or into the desert, a score survived; hut sexual re production was always greatly diminished and vege tative propagation playe a more important part. ${ }^{.3} \mathrm{Dr}$ Larcher has shown that tumors cause abrupt variations to appear in the shoots which he caused to spring in large numbers on the stems ${ }^{54}$ (galls, excrescences, "witches brooms," etc.)

Finally, according to Blaringhem, ${ }^{55}$ "it is in mutila tions that we must seek the possibility of obtaining new forms." Grafts are mutilations, and the pre tended hybrids through grafts are doubtless variation of traumatic origin. Mutilations also of a single plant which naturally cannot furnish graft hybrids, probably cause morphologic and even physiologic variations; they may increase precocity and productivity, transform late maize into early maize (Blaringhem) ${ }^{68}$ or advance the maturing of tomatoes by a month. ${ }^{67}$ The amputation of large branches (rejuvenation "dehorning") transforms sterile old trees no longer bearing either leave or fruit into productive trees. ${ }^{88}$

Practical horticulture also makes use of annular in cision as well as grafting to increase the fecundity of plants. By annular incision of the root J. Brzezinski provoked in the Raifort (normally sterile) the formation of perfectly formed seeds; the fecundated ovules, better nourished, soon became larger and their embryos developed.

\section{§ 3.-variations in agriculture}

The variation does not affect the entire plant; it affects a given member of character and causes poly morphism of the vegetative organs by an "infinitely varied modeling of a few fundamental forms." 60

Variations of form displays itself immediately, first striking the eye, and we wrongly attribute to it a value of its own, whereas it is merely the result an the indication of a variation of function or of com position. Morphologic variations are of interest only to the horticulturist.

Physiologic variations are important to the agriculturist, who must prevent their return if they ar prejudicial, and fix them if they are profitable. Diminution of yield, of vigor, of resistance to disease enfeebling of special desire aptitude, are all consequences of secondary importance for food or fodde plants, but qualities which greatly depreciate the value of industrial plants because of the lack of uniformity in the crop. ${ }^{61}$ Inversely, variations may exaggerat desirable qualities (hardiness, productivity, etc.) and suppress unfavorable characters (thornless cactus and furze).

49.J. Dufrenoy : Remarks on the Occasion of the Modifica tions Produced by the Marine Wind on the Male Inflorescence
of the Maritime Pine, C. R. Soc. Biolog of the Maritime Pine. C. R. Soc. Biolog., p. 174, Feb. 17, '17.
50Th. Mechan: The Law Governing Sex. Proceed Ac. Nat. ${ }^{5}$ Th. Mechan: The Law Governing Sex. Proceed Ac. Nat.
Sc. Phila., 1878, p. 26, and Giard: Variations of Sexuality in

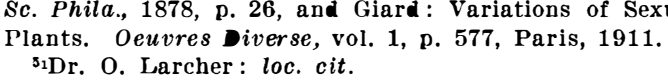

${ }^{5}$ Modification of Germ Plasm. Ann Mo. Bot. Garden, vol. II. p. $252,1915$.
s3The Eleodea

method in America, but asexually in Europe where the flowe ${ }^{Q}$ has not been observed. (Dr. Lalesque : loc, cit.)

${ }^{64} \mathrm{O}$. Isarcher : Contribution to History of Tumors of the Stem * * * Report 1 st Internat. Congress of Comparative Pathology, Paris, Oct., 1912

534"Abrupt Transformation of Living Creatures," Paris, 1911 ${ }^{6}$ This variety, a soi-disant new one, has,
fon, no practical value and is not stable.

${ }^{57}$ Bassi ; Munro (at Rosthern) makes a résume of his obser
. vations in the following table:

Tomatoes Prune-First Ripe Fruits-Varieties: Alacrity, Rennies, Sep. 2; Earliest Round, Aug. 10.

Tomatoes not Pruned-First Ripe Fruits-Varieties: Alacrity, Rennies, Sep. 10; Earliest Round, Sep. 10

Report Experimental Farms, Ottawa, 1916.

${ }^{68}$ M. B. Davis: The Restoration of the Neglected Orchard Ottawa, 1914, and E. Fau: Rejuvenation of Fruit Trees an ${ }^{50}$ Bull A cad. of Sc, of Cracow, p. 17, 1916

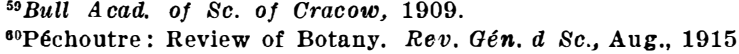

aj. R. Carracido: loc. eit.

\section{§ 4.-ECOLOGIC FACTORS OF SEXUALITY}

Varions in sexuality are those most alluring to the biologist. Dr. O. Larcher calls attention ${ }^{62}$ to the fact that in plants as well as in animals, mutilations, or even mere troubles of nutrition, are sufficient to produce male characters in female specimens.

In a member which ought to be fertile ecologic factors may cause the function of reproduction to be replace by the function of nutrition, of multiplication, or of protection. ${ }^{\text {ss }}$

A young shoot of the pine will bear, according to the conditions of the locality, fertile branches (flowers of or ${ }^{\ominus}$ ), adventitious branches (protectors of
stalks), or assimilators (with green needles).

"The causes of sexuality are determined as a func-

tion of the physiologic state of the organism and of the composition of the milieu. .4 $^{4}$

Sexuality appears to be in its very essence a response to the operation of ecologic factors. When a cycle of vegetative activity is closed by arrival at a state of senility it cannot be repeated except as the consequence of some process of rejuvenation. Conjugation and the production of seed prepare, or form a part of, the most common process. $^{\text {es }}$ But there are others.

When a bud develops immediately without a period of rest it presents no sign of rejuvenation; it continues the cycle until senility is arrived at, taking for its point of departure the age of the axis at its point of insertion. But the bud which does not develop immediately can not resume its vegetative activity without a phase of rejuvenation.

When the seed germinates the stem of the plantlet bears, above the cotyledons. prinordial leaves which have not the same form as adult leaves.

When the buds of peronnial plants open in the spring after the winter rest, the young stem which they develop stili bears primordial leaves, before forming adult leaves. When traumatisms or the mortification of terminal shoots causes adventitious or lateral dormant buds ${ }^{87}$ to develop, the stem which they produce first bears primordial leaves. ${ }^{\text {es }}$

The example of the Ulothrix shows that between a sexual rejuvenation and sexual rejuvenation all the intermediates are to be found: the adult filaments of this little fresh water Alga produce at the beginning of winter agametes, which all develop directly into adult algæ, and later they produce gametes capable of developing indifferently after conjugation or without conjugation. Finally, in the spring ecologic conditions are such that all the gametes are obliged to be conjugated in order to develop, and not to perish. ${ }^{80}$

Though conjugation is not the sole mode of rejuvenation, does it remain, as is believed by Maupas, ${ }^{70}$

6: V. Cayla: Spontaneous Variation in Plants. Vie Agric., vol. IX, p. $313 ; 1916$. In the Vosges the listilleries and starch factories require, in orler to prosper. that the cultivation of pure and fixed breeds shall give them potatoes with
an invariable percentage of nitrogenous matter and of starch. an invariable percentage of nitrogenous
(Ann. Se. Agron. Fr. et. Etrang, 1914).

(Ann. Se. Agron. Fr. et. Etrang, 1914).
The rubber industries suffer greatly from the non-uniformThe rubber industries suffer greatly from the non-uniform-
ity of the latex. (The Present State of the Synthesis of Rubity of the latex. (The Present State of the Synthesis of
ber. Rev. Gén. d. Sc., p. 151 (in a note), Mar. 15, 1917. ${ }^{63} \mathrm{Dr}$. O. Larcher : Contribution to the IIistory of Female Birds in which the External Attributes of the Male Sex Have Birds in which the External Attributes of the Male Sex Have
Developed. Bull. Soc. Centr. Médécini Vétés. July 22, 1916. Developed. Bull. Soc. Centr. Médécini Vétés, July the bibliography in a separate publication.
Vide

64.J. Dufrenoy : loc. cit.

es Fauré-Frémiet : Protistology. Rev. Gén d. Sc., p. 315, 1908. ${ }^{66}$ Alex Braun (1851); G. H. Shull: Stages in the Development

B?.Jackson, 1899 ; Cushman, 1904 : Shull, 1905 ; J. Dufrenoy, ${ }^{\text {es }}$ Wounds, insect stings, can make any cells whatever of
the bark develop into adventitious buds. The pith of the branches formed does not communicate with that of the stem. (G. Bonnier and Leclerc du Sablon: Botony, vol. 1, p. 239, 1905). Perhaps buds which are adventitious
behave differently in the case of rejuvenation.

behave differently in the case of rejuvenation.
BDDr. O. Larcher: loc. cit.; T. Deveaux; P. V. Soc. Lin. Bor${ }^{{ }_{0} D \mathrm{Dr}}$. O. I Larcher : loc. cit.; T.
deaux; .J. Dufrenoy : loc. cit.

deaux; J. Dufrenoy : loc. cit.
Whether we admit Von Baer's view (1828) that "ancestors and descendants pass through the same larval phases," or that of L. Agassiz (1848) and Heckel (1868) (1866) that "the adult characters of ancestors appear in the descendants
as larval (or juvenile) characters," we are forced to regard the primordial leaves as larval organs, a reminder of the leaves possessed by the ancestors of the plant. ${ }^{70} \mathrm{Cr}$. Janet: Sporophyto gametophytic Alternation of Genera${ }^{70} \mathrm{Cr}$. Janet: Sporophyto gameto
tion in the Algae, p. 66, 1914. 
Bütschli, Hertwig, and others, the sole remedy against senile degeneracy and natural death ? $^{12}$

After Enriques, Brown (for the Splrogyræ), ${ }^{72}$ Woodruff and S. Metalvikoff ${ }^{73}$ (for the Infusoræ) have shown that the lower organisms can produce themselves indef. initely without conjugation and that, in a favorable location, they are immortal.

It is, perhaps, only unfavorable conditions, and the approach of death, which cause sexual reproduction to make its appearance. ${ }^{\text {"4 }}$

Fecundation, moreover, is nothing but a chemica effect resulting from the action of oxygen, or of cer. tain ions, ${ }^{78}$ on the substances in the ovule to make them soluble. Sexual rejuvenation is a very different phenomenon. ${ }^{\text {T6 }}$

It is, above all, the period of repose, the cyst or spore phase of the Thallophytes, the macrospore phase ${ }^{77}$ of the vascular Cryptogams, the seed phase of the Phanerogams, the winter repose ${ }^{78}$ of perennial plants of temperate countries. the repose of the Mesophytes of the desert during the dry season, ${ }^{70}$-it is latent life which characterizes rejuvenation in general..$^{80}$

The passage from latent life to active life cannot take place without excitation. F. W. Covelle has jus shown this for the buds of whortleberry Myrtille (Vaccinium), which, when it is not exposed to the frosts of winter, does not transform its amylaceous reserves into sugar, and does not develop in the spring. ${ }^{81}$

Heat and humidity suffice to release the development of the majority of seeds or winter buds. ${ }^{\mathrm{a}}$

However, the seeds of the Orchidaceae ${ }^{83}$ and of the Ericaceae $^{84-85}$ (heather, arbute berry ${ }^{86}$ ) in order to germinate must be excited by symbiotic fungi, and the same phenomenon is perhaps very general (hard seeds).

\section{\$ 5. - ORIGIN OF VARIETIES}

The action of the ecologic milieu constantly modifies vegetable types. It is within man's power to direct these variations in a favorable direction or to provoke them experimentally. It suffices to disturb the plant, by intervening in the phenomena of reproduction (crossings, castration, etc.), by operating upon the conditions (change of climate, troubles of nutrition, overfeeding, hunger, etc.), by mutilating the plant (traumatisms, grafts, etc.), or finally
various agents (radium, toxins, etc.)

${ }^{11}$ E. Maupas : Not. nêcrolog. Rev. Gén. d. Sc., p. 669, Dec. $15,1916$.

${ }^{72}$ Calkins (1902): By adding to his cultures extracts of the thyroid

${ }^{73}$ Algal Periodicity (Bull. Toir. Bot. Club, vol. XXXVIII, 1908), cited by H. Danforth: Period in Spirogyra (Bot. Mo. Gavd., p. 51, 1910)

${ }^{7}$ Immortality of the Protozoa (E. R. Réun. Biol. de Petrograd, p. 241, Nov. 29, 1916) - Metalnikoff employs a solution of Liebig's extract of meat (0.25 per cent) and changes intoxication due to the products of exchange and seintoxication due to the products of exchange and
cretion; these cultures lived 7 years without conjugation. TsMacDougal : Water Balance of Desert Plants. Ann. Bot. 1912.

76.J. R. Carracido: loc. cit.

"Normally the ovule is excited by the spermatozoon, but Loeb has shown that the sexual excitant can be replaced cal Fecundation. (translated by Anna Drzewina) p. 35, Mercure de France, Paris, 1911.

${ }^{18}$ Bonnier and Leclerc du Sablon: loc. cit., p. 1434

${ }^{79}$ The winter rest of the vine diminishes in duration a one goes toward the South, but in the forcing houses it is deemed necessary to provoke an artificial rest of 4 months to obtain regular production and ensure the duration of
the vine. (Pacottel: loc. cit., p. 72.)
so

${ }^{80}$ MacDougal: Inf. of Aridity in the Evolutionary
velopment of Plants. (The Plant World, Oct., 1909).

siThe accumulation in cysts, spores, seeds, and buds of tritive reserve substances assimilable by the rejuvenated tritive reserve substances assimilable by the rejuvenated
organism appears to be a general necessary fact. (J. Dufrenoy: C. R. Soc. de Biol., p. 9, Jan. 6, 1917).

82If of two branches of the same plant, one passes the winter in a greenhouse, while the other, extending through an opening of one of the window-panes, is exposed to the cold weather conditions of the atmosphere, only the buds of the second will develop in the spring; those of the first will remain eternally dormant. (F. W. Coville: The Wild Blue berry Tamed. Nat. Geog. Mag.

${ }_{8 s}$ MacDougal : Environic Factors. (Pop. Sc. Monthly, May, 1914) has shown that conformity to the law of Van't Hoff, the speed of transformation of reserves, and consequently ture of $10^{\circ}$ (presumably centigrade)

${ }^{84}$ Noel Bernard: Studies on Tuberization. Rev. Gén. des Sc., p. $8,1902$.

${ }^{85}$ Chevely Rayner has proved (Recent work on Endotropic Micorhiza : The New Phytologist, vol. XV, p. 167, Oct., 1916) that when sterilized the seeds of Calluna Vulgaris yield in an aseptic medium, plantlets incapable of forming roots or acquiring leaves. Inoculation with the symbiotic fungus mal plants.

${ }^{86}$ The infection of the Myrtille or of the arbutus (Dufrenoy unpublished) has been confirmed; but its necessity has not been demonstrated.
By these means we are enabled: (1) To provoke the development of dormant or rudimentary buds; (2) to modify the composition of the germinative protoplasm of the sexual cells, or of young tissues in the process of growth. and thus to alter the course of their development and their heredity. ${ }^{87}$

Rejuvenation and adaptation explain in general the olymorphism of plant organs and organisms.8

Most of ten the action of ecologic factors, of parasites, traumatisms, grafts, creates nothing new: by interfering with nutrition it imposes upon organisms period of latent life and of rejuvenation. The rejuvenation may be accomplished sexually (conjugation) or asexually. The larval characters which it causes to reappea in more or less amplitude have been described as variations. However, in response to the stimuli of the exterior conditions, races which are really new, shoul
appear slowly, or perhaps abruptly, by adaptation.

\section{GENERAL CONCLUSION}

After having been directed successively towards morphology, embyology, histology, the attention of biologists is concentrated on the relations of organisms with the external environment, with the object of determining what forces cause living creatures to vary, what is the extent of variation, ${ }^{\circ}$ and what advantage may be derived therefrom.

These studies acquire great practical importance at a time when it is vital to extract from the soil all it is able to supply, and to re-establish natural harmony over vast areas ruined by the war.

The countries which obtain the richest harvest from their soil are those which have best known how to instruct their rural populations. ${ }^{.1}$ The example of the Turkish Empire and of the Mediterranean countrie shows that, as Chateaubriand said, in the countrie where the laws of phytogeography are not respected "the forests precede man and the deserts follow him." In the bitter economic struggle, which is to be foreseen after the war, our products must compete with those of our European rivals and against those of the same kind or against cheap and abundant substitute from overseas. ${ }^{\text {22 }}$

In order to succeed we must rigorously adapt crops to conditions, strongly accentuate specialization, cease to impose upon soils crops decided upon $a$ priori. Nature will resume her rights, and the examination of natura conditions will become the basis of a rational exploitation of the land, such conditions dictating the choic of plants and the proper method of raising them.93

And production will no longer be everything. The farmer should no longer sell the raw products of his land directly. An essential condition of prosperity, fo the country in general as well as for the farmer in particular, is to export, not what the earth produces. but what man creates.

The exploitation of natural plant wealth, the cultivation in each locality of the plant best adapted to it the re-establishment between arable areas and forest areas of that equilibrium which agricultural prosperity exacts, the restoration of the destroyed vegetation in our devastated regions-these are alike questions of botanical geography. Upon their solution depends the growth of the population, the prosperity, and even the very existence of the country.

\section{The Relation Between Chemical Constitution and Physiological Action*}

THE relation between chemical constitution and physiological action occupies a definite and important place in the study of drugs. Chemical investigation of drug begins with the attempt to isolate the principle to which its activity is due. Then follow the determination of its constitution and the synthesis of a number of substances related to the parent compound, and comparison of their physiological action.

The wideness of the term "physiological action," covering as it does any action on the living organism, renders its discussion difficult. It is impossible, for

${ }^{87}$ MacDougal : loc. cit.
${ }^{88}$ The growth is only a particular case of sexual rejuvention.

${ }^{8}$ Old Fashioned Natural History. Bull. of the Scripps Inst. the Univ. of California, No. 1, Dec. 30, 1916

${ }^{\circ 0}$ D. T. MacDougal : Biological Research Institutions. Ibid. ${ }^{01}$ Rev. Gén. des Sc., Dec. 30, 1916. p. T04, and H. Sagnier: Union Francaise, No. 1, Feb. 1917

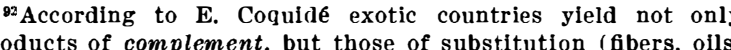
oil-cake, etc.), (The Biologic Method in the Study of the Properties of the Soil; Vie Agric., p. 41. No. 29, 1916).

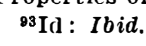

- Summary of a lecture before the Chemical Society, by Dr. F. L. Pyman.-Reported in Nature. nstance, to compare the bactericidal action of phenol with the hypnotic effect of diethylbarbituric acid, or with the anesthetic action of cocaine, for the same superficial signs of physiological action may be due to widely different causes. Examples of physiological action are not wanting. Compounds of similar constitution generally possess a characteristic group-smell, whilst each member may have a specific odor. Sense of taste also provides an occasional means of discrimination not only between side-chains of different length, but also in certain cases between stereoisomerides.

Stereochemical influences often exercise profound effects, particularly on nerve-endings. Thus $l$-hyoscyamine has about a hundred times the mydriatic action of $d$-hyoscyamine, and $l$-adrenine many times the pressor effect of the dextro-compound. Asymmetry of a nitrogen atom may also condition a difference, as in the case of the $\alpha$ - and $\beta$-methochlorides of $l$-canadine. The cause of this variation still remains in doubt.

The influence of physical properties, such as solubility in different media, may be of importance, and it has been shown that for a particular series of aliphatic compounds their narcotic effect on tadpoles was proportional to the partition-coefficients of their solubilities in oil and water.

As an indication of the effect of chemical properties, it has been shown that whilst certain basic dyes stain the grey nerve substance, their sulphonic acids do not. This difference suggested that bases, liberated in the blood-stream by alkalis, are extracted by the nerve ubstance, whilst their sulphonic acids remain in solution as alkali salts.

In the case of alkaloids it is a general rule that the introduction of a free carboxyl group profoundly modifies the physiological action. Benzoyl ecgonine, of which cocaine is the methyl ester, has no local anesthetic action; whilst quitenine, obtained from quinine by oxidation of the vinyl group, is non-toxic. Formation of quaternary salts has also a considerable effect. For instance, papaverine has a strychnine-like action which is missing in its methochloride, and reappears in its reduction product laudanosine.

In the many cases in which members of a group of compounds of similar constitution resemble one another in physiological action it is of interest to observe the effect of slight chemical alterations. The following four pieces of work were then outlined: (1) Tropeines (acyl derivatives of the amino-alcohol tropine); (2) aminoalkyl esters (formed by the esterification of an acid with an alcohol containing an amino-group); (3) adrenine and the amines (adrenine is the active principle of the suprarenal gland) ; (4) protozoacidal drugs. The results of experiments that have been made on the relative toxicity to infusoria of a number of cinchona derivatives, with a view to their employment in the treatment in malaria, indicate that ethylhydrocupreine was the most active, but they do not admit of any certain conclusions as to the relation between their hemical constitution and protozoacidal action.

Experiments have also been made on the relative toxicity of the ipecacuanha alkaloids to amobæ, and they indicate that the full amobacidal action characteristic of emetine is exhibited only when the nucleus is intact.

\section{Contraction of Volume of Certain Substances} When Dissolved in Water

From the specific gravities of certain substances, that of water at different temperatures, and those of the solutions of these substances in water, Mr. J. N. Rakshit has calculated the contraction of volume resulting when a fixed quantity of each substance is dissolved in increasing quantities of water. The results are tabulated in the Proceedings of the Indian Association for the Cultivation of Science (vol. 111., part iv.), the substances dealt with being hydrochloric, sulphuric, nitric, formic, acetic, and tartaric acids; stannic and sodium chlorides; ammonia, sodium, and potassium hydroxides; methyl, ethyl, propyl, iso-butyl and isoamyl alcohols, glycerol, phenol, dextrose, lævulose, maltose, invert- and canesugars, acetone, chloral hydrate, acetonitrile, and nicotine. Study of the figures obtained shows that in some cases the contraction of volume increases with the increase in dilution, but in several others as the dilution increases a point of maximal contraction is observed. The maximum contractions are constants, and different for different substances. In the cases of sodium chloride and of acetic and sulphuric acids the contraction of volume at all dilutions diminishes as the temperature rises. It is not yet known whether this phenomenon is water and of the solute.-Nature. 